\title{
AÇÃO DIDÁTICA DE ENSINO SIMULADO: UMA PESQUISA-AÇÃO ACERCA DO CONTEÚDO DE MRP
}

\author{
TEACHING SIMULATION: \\ AN ACTION RESEARCH STUDY ON MRP CONTENT
}

Recebido em: 04/10/2013 - Aprovado em: 20/12/2013
Avaliado pelo sistema double blind review
Editora Científica: Manolita Correia Lima

\section{CRISTIANO HENRIQUE ANTONELLI DA VEIGA chadaveiga@gmail.com \\ UNIVERSIDADE FEDERAL DE SANTA MARIA}

LENIR BASSO ZANON

UNIVERSIDADE REGIONAL DO NOROESTE DO ESTADO DO RIO GRANDE DO SUL

\section{LUIS CARLOS ZUCATTO}

UNIVERSIDADE FEDERAL DE SANTA MARIA

\section{RESUMO}

O presente trabalho apresenta e discute uma proposta de ação didática de ensino simulado, elaborada com base no conceito de conhecimento pedagógico do conteúdo (SHULMAN, 2005) e da epistemologia da prática da reflexão-na-ação e sobre a ação (schön, 2000), com o objetivo de propiciar novos entendimentos acerca do conteúdo de Material Requirements Planning - MRP I, em aulas de Administração da Produção de um curso de Bacharelado em Administração. A proposta da atividade de ensino foi subdivida em duas aulas, sendo a primeira denominada de apresentação do conteúdo científico e a segunda denominada de vivências mediadas. Para investigar o desenvolvimento da proposta utilizou-se como caminho metodológico a pesquisa-ação por meio da realização de um exercício elaborado pelo docente da disciplina. Após a realização da atividade didática, verificou-se que os estudantes melhoraram a compreensão sobre os conceitos e da lógica de cálculo e operacionalização do MRP I.

Palavras-chave: ensino de Administração; ação didática simulada; conhecimento pedagógico do conteúdo; Material Requirements Planning-MRP.

\section{ABSTRACT}

This paper presents and discusses a proposed simulation teaching action based on the pedagogical knowledge of content concept (SHULMAN, 2005) and the epistemology of practice of reflection-in and on-action (SCHÖN, 2000), aiming to explore a different understanding of Material Requirements Planning - MRP I in the Production Management classes of a Bachelor's in Management. The teaching activity was subdivided into two classes, the first denominated the presentation of the scientific content and the second, mediated experiences. The development of the proposal was investigated using action research methodology through an exercise prepared by the teacher of the subject. Upon completion of the didactic activity, it was found that students improved their understanding of the concepts and logic of calculation and operationalization in MRP I.

Keywords: management teaching; didactic action simulation; pedagogical knowledge of content; Material Requirements Planning - MRP. 


\section{INTRODUÇÃO}

Este artigo trata de uma proposta de desenvolvimento pedagógico do conteúdo do ensino de Administração da Produção, especificamente, no que concerne ao estudo das Necessidades de Planejamento de Materiais (MRP I - Material Requirements Planning) mediado pelo uso de simulação orientada em sala de aula.

A pesquisa na área de Administração da Produção no Brasil, nos principais periódicos da área, apresenta crescimento no número de trabalhos publicados entre os anos de 2007 até 20II. Sobre as autorias dos estudos, observou-se que a maioria dos autores tem vínculos com programas de pósgraduação em Administração e de Engenharia de Produção e os principais temas são a gestão enxuta, o gerenciamento da cadeia de suprimentos e o processo de desenvolvimento de produtos (ROMAN; MARCHI; ERDMANN, 20I3).

Muito embora essas pesquisas estejam vinculadas a programas de pósgraduação, seu foco está no estudo que comprove a funcionalidade de técnicas ou teorias da área, sem, no entanto, se identificar pesquisas voltadas para o ensino e aprendizagem de gestão da produção, muito embora um dos papéis dos programas de pós-graduação seja o de preparar docentes qualificados para o ensino da área (BRASIL, 2006).

Embora o tema acerca dos sistemas MrP seja um tema consolidado tanto para as organizações como para academia, ainda são poucos os estudos sobre seu desenvolvimento didático com ênfase no ensino de graduação em Administração. As estratégias didáticas dominantes, conforme Platt e Klaes (2010), ainda encontram-se focadas na apresentação oral do conteúdo pelo docente e na realização de exercícios propostos, muitos deles oriundos dos livros didáticos disponíveis no mercado e na realização de prova escrita para avaliar o grau de conhecimento dos estudantes.

Uma dificuldade para a mudança dessa prática didática, conforme Satolo (20II), encontra-se na necessidade de se criar estratégias de ensino pertinentes, devido à especificidade das características técnicas envolvidas, como no caso das possibilidades de configuração de simulações didáticas. Ao se investigar estudos de caso com este foco, encontram-se exemplos 
como o de Depexe et al. (2006) que descrevem as características técnicas dos produtos, as tabelas de coleta de dados e os resultados do processo manufatureiro simulado, mas não apresentam uma estrutura didática utilizada para o seu desenvolvimento.

A constatação da relação dicotômica entre o entendimento, pelos estudantes, das teorias denominadas acadêmicas e/ou científicas da área de Administração da Produção estudadas em aula e as situaçõesproblemas típicas ao contexto das organizações fabris foi o que motivou a elaboração dessa proposta didática de ensino. Na tentativa de estabelecer uma relação articuladora entre essas duas dimensões no meio educacional, fez-se necessária a busca do entendimento crítico e reflexivo sobre as ações operacionais do universo fabril e as teorias disponíveis para a consecução dessa atividade.

Este contexto leva a se estabelecer a seguinte questão que orienta o estudo: como organizar e conduzir aulas com foco no conhecimento pedagógico do conteúdo vivenciado, por meio de uma ação didática simulada, que contribua para o entendimento teórico-prático dos conceitos do MRP? O caminho metodológico baseia-se na pesquisa-ação (THIOLLENT, 2003) por meio de um estudo exploratório, de investigação de uma proposta didática de simulação das práticas referentes ao conteúdo de MRP I, desenvolvidas com estudantes de graduação matriculados na disciplina de Produção, Materiais e Logística no curso de Bacharelado em Administração de uma Universidade Federal.

A estratégia de gestão do ensino em discussão neste estudo se contrapõe à reprodução mecânica do conteúdo em aula, extrapolando os limites da estratégia de transmissão-recepção. Busca-se, desta forma, articular pedagogicamente os conceitos acadêmicos e as vivências organizacionais decorrentes dessas teorias, buscando-se propiciar ao estudante uma visão menos idealizada da sua futura atuação profissional (SANTOS, 2009; MATTOS, 20Io). Uma tentativa de romper com essa visão está relacionada com a adoção de didáticas com foco nas vivências formativas, pelas quais o futuro profissional possa desenvolver outros aprendizados, de forma situada, frente a situações-problema da prática. 
Ao final do estudo é apresentada uma síntese da organização didática desta estratégia, de ensino de forma a possibilitar aos docentes mediar os conceitos da área, articuladamente, com possibilidades do uso em um ambiente simulado em aula. Essa articulação dinâmica entre o estudo do conceito e suas possibilidades de utilização no contexto de sala de aula, possibilita ao docente criar condições de significação da linguagem científica, acompanhada da compreensão de suas implicações no contexto real em que serão utilizados pelos acadêmicos quando egressos do curso.

Cabe ressaltar que a estratégia de ensino do tipo expositivo-dialogada é utilizada em uma das etapas da proposta com o objetivo de realizar a apresentação da tradição na área e para desenvolver cognitivamente os aspectos técnicos do conteúdo. O que se advoga é que sejam utilizados os estilos tradicionais de aula conjuntamente com estratégias inovadoras de desenvolvimento do conteúdo, possibilitando uma articulação tanto cognitiva, quanto vivencial das teorias estudadas.

Este artigo encontra-se estruturado em duas grandes temáticas. A primeira subdivide-se na análise de publicações que abordam o conhecimento pedagógico do conteúdo e a perspectiva da reflexão na formação do professor, as considerações legais sobre o ensino de Administração da Produção, seguindo as fundamentações teóricas da área e finalizando com as ações cotidianas de algumas organizações manufatureiras Brasileiras, que utilizam a ferramenta do MRP para programar e controlar sua produção.

Na segunda parte é apresentada a descrição da estratégia de ensino proposta, de forma a caracterizá-la como vivência mediada, em que o estudante não realiza apenas operacionalmente as atividades, mas que as realize, numa primeira etapa, de forma vivencial simulada e orientada pelo docente, o qual media os conceitos e em seguida torna possível a simulação da prática e finaliza potencializando o desenvolvimento de novas teorias. O estudo é concluso fazendo-se uma análise das observações verificadas nesse processo. 


\section{FORMAÇÃO DA PRÁTICA DOCENTE COM UM OLHAR AO ENSINO DA ÁREA DE ADMINISTRAÇÃO}

A presente tematização inicia com um debate acerca das atividades docentes e seus desdobramentos para a ação pedagógica, em caráter geral, e posteriormente algumas considerações sobre o ensino em Administração.

No que tange às questões relacionadas às atividades docentes, Puentes, Aquino e Quillici Neto (2009) realizam uma discussão sobre os conhecimentos necessários para o trabalho docente em geral. Os autores relatam que, apesar do tema ser amplo, a pesquisa acerca da profissão docente está demarcada pela pluralidade e heterogeneidade de tipologias propostas, embora os significados conceituais sejam similares entre os autores por eles pesquisados.

Na tentativa de realizar uma proposta de conhecimentos necessários ao trabalho docente, Shulman (2005) propõe sete categorias para formar a base de conhecimento do professor. Salienta-se que uma delas é o conhecimento didático do conteúdo, o qual tem como foco principal a matéria que está em estudo e a didática utilizada durante a realização da aula. Essa categoria tem especial importância para o docente.

A compreensão do trabalho do professor não pode ser limitada à tarefa de um especialista técnico em determinada área, mas na capacidade pedagógica de como determinados temas e problemas podem ser organizados, representados e adaptados para haver um entendimento dos estudantes para além da resolução de provas, mas para que esses consigam desenvolver os seus aprendizados. Deste modo, o trabalho docente está em promover atividades que estimulem os estudantes a aprender, de modo que o ensino dê suporte para o aprendizado desses (JARAUTA-BORRASCA; MEDINA-MOYA, 2009).

Pode-se destacar a importância desse aspecto nas pesquisas de Seethamraju (2007), que ao realizar o estudo de utilização de um software comercial de ERP para o ensino de graduação e pós-graduação em Administração na Universidade de Sidnei (Austrália), constatou que muitos dos materiais e manuais são editados para uma versão de treinamento empresarial e não 
são adequados para o ensino universitário. O mesmo fato também ocorre com livros-texto utilizados em cursos de graduação e nos programas de pósgraduação. Buscando preencher essa lacuna, professores da Universidade de Montreal (Canadá), desenvolveram um simulador computacional que aproxima pedagogicamente, em tempo real, as ações desenvolvidas pelos estudantes que oportunizam contextos ricos tanto para o desenvolvimento cognitivo, quanto colaborativo dos grupos (LÉGE et al., 20I2).

Assim, uma estratégia de ensino e de aprendizagem utilizada com frequência nos cursos de administração é a do Jogos de Empresas. Mota, Melo e Paixão (2012), advogam que esta forma de se trabalhar os conceitos da área proporciona significativas contribuições na formação do futuro administrador. Ela auxilia no processo de tomada decisão, possibilita simulação de atividades do cotidiano organizacional, potencializa habilidades de relacionamento interpessoal e trabalho em equipe e permite a aplicação de conhecimentos construídos ao longo do curso.

Estudos realizados no Brasil com estudantes de estudantes de pósgraduação com o uso de jogos de empresas computacionais desenvolvidos para o ensino de PCP - Planejamento e Controle da Produção mostram que esta didática ainda apresenta algumas lacunas as serem superados como o desenvolvimento de metodologias de avaliação, da dificuldade inicial dos estudantes em entender as variáveis envolvidas na simulação e não exploração da reflexão das dinâmicas realizadas para o desenvolvimento dos estudantes (DIAS; SAUAIA; YOSHIZAKI, 20I3).

Uma visão semelhante foi observada por Piana e Erdman (2013) com estudantes Portugueses acerca do uso de jogos de empresas computacionais, acrescido dos fatos já mencionados, da necessidade de uma sistemática de avaliação qualitativa que valorize o aprendizado mediante a análise dos erros ocorridos e para que o estudante não fique centrado apenas no resultado final de quem ganhou o jogo.

Outro debate acerca do processo de ensino e de aprendizagem é o que foi proposto por Schön (2000), que objetiva uma aproximação reflexiva das atividades práticas, principalmente para aquelas áreas do conhecimento em que se exige o desenvolvimento de habilidades técnicas dos futuros 
profissionais. O saber profissional, por exemplo, o pensar como um administrador será apreendido cognitivamente pelos estudantes, mas também terão a possibilidade de raciocinar nas instâncias problemáticas da área, nas conexões do conhecimento geral e para os casos em particular, baseados em uma atividade prática.

A epistemologia da prática defendida por Schön (2000) é composta de algumas proposições que os professores necessitam levar em consideração no momento de utilizar esta estratégia de ensino. Sua proposta está focada, inicialmente, no movimento da reflexão-na-ação, propondo que seja construída uma epistemologia da práxis educativa por meio das seguintes etapas: produção do conhecimento na ação, reflexão na ação, reflexão sobre a ação, e reflexão sobre a reflexão na ação.

De acordo com Stein (I997), entende-se como epistemologia a tentativa de preencher a lacuna existente no universo de nossas proposições empíricas, nas distâncias que nossas teorias nos separam da experiência cotidiana. Zeichner (I992) comenta que a reflexão-na-ação é constituída de processos de pensamento que são utilizados no transcurso da ação, com os quais o professor busca conseguir que os estudantes construam respostas mais adequadas aos problemas propostos. Ao término da ação, o professor pode realizar uma retrospectiva narrativa dos fatos ocorridos buscando desenvolver o processo do pensamento de reflexão-sobre-a-ação.

Ghedin (2006) salienta que apesar das contribuições significativas da proposta de Schön (2000), o conhecimento também pode vir de aula prática-reflexiva, mas não é somente por esta ação pedagógica que se pode desenvolvê-lo. Salienta-se que o processo educacional exclusivamente prático também implica numa dimensão teórica, seja ela implícita ou explicita. Em uma visão geral, o que se propõe é a realização da articulação entre ambas.

Cabe ressaltar, apoiado nas ideias de Vigotsky (2008), que os processos de formação de conceitos induzidos de forma experimental possibilitam um reflexo do desenvolvimento da vida real. Esses procedimentos permitem identificar os processos-chave que estão envolvidos e posteriormente, no caso da educação, trabalhados pedagogicamente para uma compreensão 
de como os conceitos e vivências podem ser desenvolvidos e implantados na vida real. Leontiev (1998, p.63) salienta que embora em uma primeira e superficial visão de que aparentemente um jovem não apresente mudanças das relações humanas ocupadas no ambiente escolar para o das relações de emprego é meramente aparente. Quando o jovem estudante é "[...] diligente iniciante, orgulhoso e satisfeito em sua consciência de ser um trabalhador, torna-se amanhã um dos entusiastas da produção avançada". Desta forma, percebe-se a importância do papel condutor da educação e da atitude do estudante de forma a propiciar o desenvolvimento de sua psique e da tomada da consciência dos processos de suas condições reais de vida.

Nicolini (2003) comenta que o ensino contemporâneo da Administração exige uma complexidade de conhecimentos que o processo de aprendizagem usualmente adotado parece ainda não ter sido considerado na maioria dos projetos pedagógicos. Um dos motivos alegados pelo autor é que os métodos de ensino predominantes, nesta área, são originários da epistemologia tradicional positivista, centrada na ação expositiva do docente.

Maranhão e De Paula (2008, p.8) também realizaram uma crítica de diversos pontos das práticas de ensino dos cursos de Administração focado nos chamados "manuais de gestão" ou nos "top-management". Outro ponto a ser debatido é a articulação e análise do conteúdo apenas com uso dos materiais didáticos padronizados, os quais passam a ser reprodutores de um sistema dominante, limitando-se apenas aos exemplos e exercícios propostos por estes materiais, os quais buscam ajustar a um determinado padrão de comportamento e consciência sobre os temas da área.

Outra análise que Maranhão e De Paula (2008) fazem sobre o trabalho do docente da área de administração é quando esse não se questiona se o conteúdo estabelecido sobre os temas disponibilizados são pertinentes, bem como suas proposições didáticas e metodologias de avaliação. Atitude como essa subtrai o papel do professor a mero facilitador de conteúdo bem como limita a sua capacidade de escolha e adequação do que deveria ser ensinado para o contexto de cada sala de aula, sem o descumprimento das diretrizes curriculares nacionais. Esta prática, além de dificultar o enriquecimento das experiências que os estudantes podem trazer do seu cotidiano, limita 
a interpretação dos assuntos e o desenvolvimento intelectual desses estudantes para que possam se utilizar de conhecimentos apreendidos em aula para as suas futuras atividades profissionais.

Na visão de Closs, Aramburu e Antunes (2009), o ensino em administração, no Brasil, carece de maior integração curricular e interdisciplinaridade, problematização de situações com caráter reflexivo sobre as mesmas e utilização adequada das novas tecnologias da informação e comunicação. Por outro lado, há excessiva ênfase em técnicas e ausência de valores e atitudes. As autoras concluem, ainda, que se faz necessária uma visão da avaliação como um processo contínuo e não pontual. Villardi (2010) argumenta que há uma tradição do ensino de administração baseada em estudos críticos, focada no entendimento teórico das práticas organizacionais, além da centralidade do desenvolvimento do processo educativo. Assim, na maior parte dos casos, a estratégia de ensino reside na ação expositiva do docente, deixando o estudante em uma situação de passividade no sentido da realização da análise dos resultados dos estudos apresentados e na identificação de ações que não se realizaram.

Outra proposta de atividade educativa está na aprendizagem baseada na ação ou na aprendizagem vivencial. Buscando identificar a correlação entre o dilema do conhecimento técnico e o desempenho real, Oliveira et al. (2010), reproduziram no Brasil experimentos realizados no exterior cujo objetivo era identificar as correlações entre o nível de conhecimento acadêmico e o desempenho na prática gerencial com o uso de atividades educacionais vivenciais. Como resultado, o estudo destacou que o fator de maior intensidade manifestado pelos estudantes foi o interesse na experiência vivencial, pois ele torna-se agente do processo de aprendizagem, pelo seu envolvimento ativo e determinante nas tarefas propostas. Embora as atividades acadêmicas de aprendizagem vivencial tenham sido desenvolvidas como alternativa ao método passivo de ensino, são necessários mais estudos e pesquisas para maior reconhecimento na área de educação em Administração, apesar de que, conforme Villardi (20I0), essa abordagem já esteja sendo utilizada para o desenvolvimento gerencial nas organizações empresariais. 


\section{CONSIDERAÇÕES ACERCA DO ENSINO DE ADMINISTRAÇÃO DA PRODUÇÃO}

O estabelecimento da atividade profissional de Administrador (BRASIL, 1969), bem como o amparo para a sua formação educacional (BRASIL, 2005), faz com que haja desdobramentos de aspectos legais na preparação do estudante do Curso de Bacharelado em Administração em relação às questões da área do conhecimento da Produção. As Diretrizes Nacionais Curriculares consideram, como conteúdo de formação profissional, o ensino de operações, explicitadas nos Projetos Pedagógicos dos cursos por meio dos planos de componentes curriculares.

Os desdobramentos dessa ação educativa podem ser configurados em dois vieses significativos: um deles estabelecido como Científico, conforme consta da lista de área do conhecimento do Conselho Nacional de Desenvolvimento Científico e Tecnológico - CNPQ, na área de Ciências Sociais Aplicadas, denominada de Administração da Produção (BRASIL, s.d.); e o outro, focado para a ação cotidiana das organizações empresariais, que, conforme Tubino (2008) se utilizam dos conhecimentos da Administração da Produção, aplicando-os aos processos produtivos para a transformação de bens e de serviços.

Como campo científico, Santos e Alcadipani (20ro), relatam a importância e o crescimento da pesquisa na área acadêmica da gestão. A pesquisa nesta área vem apresentando crescimento ao longo dos últimos 70 anos, porém, paulatinamente, ela passou a se construir em bases de teorizações abstratas ou tentativas igualmente abstratas de modelagem de aspectos organizacionais, furtando-se a analisar suas implicações no que e como estas teorias afetariam o cotidiano das pessoas no âmbito organizacional.

Por outrolado, ao se buscar esta transposição da categoria do conhecimento do conteúdo para a do conhecimento pedagógico do conteúdo, conforme propôs Shulman (2005), verificam-se algumas críticas pelo fato de que conceitos e práticas da Administração da Produção seriam utilizados literalmente, porém de maneira inadequada, para a educação. Pode-se perceber que há uma confusão de entendimento quanto aos aspectos de 
formação de uma área do conhecimento, legalmente estabelecida para a formação do profissional em Administração.

Dadas às práticas pedagógicas que se utilizam unicamente de conceitos teóricos e explicativos para o ensino da Administração da Produção, se considera que seja oportuna a discussão acerca de outras didáticas para o desenvolvimento de seu ensino, investigando suas limitações e potencialidades, seus aspectos críticos e pontos que ainda necessitam de novos campos de sua pesquisa. Faz-se também necessário um debate sobre uma prática acadêmica adotada para este campo do saber, realizada em sala de aula. As mudanças observadas são de caráter exógeno, voltadas a ajustes de conteúdos em componentes curriculares para atender a uma demanda do ambiente ou de promover diferenças entre instituições concorrentes. "O que se vê, claramente, é que os cursos de Administração ficaram adormecidos por quase trinta anos" (ARAGÃO, 2008, p.I43). Este cenário remete à necessidade de se buscar fundamentações pedagógicas para o desenvolvimento acadêmico neste campo.

Embora os fundamentos teóricos e técnicos da Administração sejam estudados há mais de cem anos, a pressão pela competitividade e qualidade, principal característica da manufatura dos anos I980 e I990, propiciaram-lhe um caráter significativo para o foco estratégico das organizações (CORRÊA; GIANESI, I994). Como a característica dos primeiros anos do Século xxi é a crescente e veloz quantidade de produtos inovadores lançados ao mercado, essas inovações estão exigindo novos conceitos e/ou outros olhares sobre as práticas de manufatura já existentes para atender às novas demandas. Assim, as pessoas que labutam em sistemas produtivos viram ser ampliadas suas atribuições para além das responsabilidades de execução dos processos de transformação dos produtos ou serviços, para participantes, como membros integrantes da equipe de pesquisa e desenvolvimento, bem como uma parte que auxilia na decisão desde a elaboração até a estruturação das ações de inovação (KRAJEWSKI; RITZMAN; MALHOTRA, 2009).

Os sistemas produtivos são estudados, tradicionalmente, como conjuntos de atividades de entradas de insumos com objetivo de produzir saídas de bens ou serviços, de acordo com padrões previamente estabelecidos 
(HARDING, 1992). no entanto, existe outra abordagem que valoriza não somente as questões relacionadas às máquinas e aos processos da empresa, mas busca valorizar também os componentes intangíveis envolvidos nos processos empresariais, ou seja, as interações humanas subjetivas.

Nessa perspectiva, os processos produtivos são frutos das relações existentes, no âmbito empresarial, pelas interações entre as pessoas e suas intervenções para a consecução daqueles. Fröner (20I3, p.82) manifesta que "a relação humana no contexto do processo produtivo depende do que os humanos oferecem (como inputs) para esta relação e, ainda, de como tal relacionamento é sentido pelos atores da interação (como outputs)". Ou seja, é na qualidade do processo das relações humanas que se propicia o desenvolvimento dos processos empresariais, tanto administrativos quanto produtivos. Ao analisar a produção sob essa perspectiva, verifica-se a importância do papel do administrador da produção para que o desempenho operacional seja atingido de acordo com os objetivos estabelecidos.

Mediados pelas inter-relações empresariais, os processos de transformação também necessitam ser pensados e executados em termos de prazos. Para que as etapas dos sistemas produtivos possam ser gerenciadas, faz-se necessária a definição de pontos para o seu controle e verificação. Assim, no contexto da fábrica, as pessoas que laboram no setor de Planejamento e Controle da Produção (PCP) são as responsáveis pela condução dessas interações e pela organização das funções de manufatura. Para Slack, Chambers e Johnston (2002) o gerenciamento eficiente dos processos inicia pela coleta de dados que servem de base para aplicativos informatizados, denominados de Enterprise Resource Plan - ERPS. Tubino (2008) lembra que os atuais ERPs tiveram sua evolução baseado nos conceitos do Material Requirement Planning - MRP, desenvolvidos na década de I960. Já, Krajewski, Ritzman e Malhotra (2009) argumentam que depois de definidas as quantidades que serão necessárias para a manufatura do produto, parte-se para a liberação das ordens de produção ou de compras. Nesse momento, é levado em consideração o tempo de atendimento de cada item.

Compreende-se o MRP I como uma técnica de cálculo que permite estabelecer as quantidades de compras de materiais ou a produção de itens 
necessários para a fabricação de um ou vários produtos manufaturados. O seu cálculo é baseado na "lista de materiais (Bill of material), obtida por meio da estrutura analítica do produto, também conhecida por árvore do produto ou explosão do produto, e em função de uma demanda dada" (MARTINS; LAUGENI, 2006, p. II8-II9). Depois de definidas as quantidades que serão necessárias para a manufatura do produto, parte-se para a liberação das ordens de fabricação ou de compras. Nesse momento é levado em consideração o tempo de atendimento de cada item (KRAJEWSKI; RITZMAN; MALHOTRA, 2009).

De maneira geral, conforme Tubino (2008), os desdobramentos operacionais do MRP I ocorrem no ambiente fabril, por meio da atuação do setor de PCP. Os profissionais que trabalham nesse setor são os responsáveis por verificar o Plano Mestre de Operações - PMP, identificando os recursos que serão necessários para as ações de manufatura, a existência de possíveis gargalos e realizar a programação da produção, emitindo e distribuindo as ordens de compras, de fabricação e de montagem, a fim de possibilitar a confecção do produto final. Para que isso ocorra, faz-se necessário um acompanhamento permanente no chão de fábrica, em vista de monitorar como estão sendo desenvolvidas as etapas produtivas e verificar se tudo está ocorrendo de acordo com o planejado ou, caso sejam verificadas lacunas, propor medidas corretivas para a sua solução.

A evolução dos sistemas de informações gerenciais propiciou o desenvolvimento do Manufacturing Resourse Planning - MRP II, o qual possibilitou o gerenciamento dos recursos utilizados para a manufatura (TUBINO, 2008). O MRP e MRP II foram os precursores dos sistemas produtivos, sendo que nos anos de I980 foram desenvolvidas várias outras formas de gerenciar a produção, quando o foco passou a ser a gestão visual da manufatura, redução dos estoques, bem como da introdução do conceito da produção puxada e na busca de redução dos tempos de set-ups ou de preparação de máquinas (SHINGO, I996).

Embora os temas emergentes da manufatura sejam os tópicos mais pesquisados nos últimos anos (ROMAN; MARCHI; ERDMANN, 2OI3), O MRP ainda tem um escopo de aplicação e desenvolvimento de seus conceitos 
e sistemáticas de cálculos no meio empresarial (SLACK; LEWIS; BATES 2004), fato este que ainda se justifica o seu estudo, no contexto do ensino de graduação, como conteúdo constituinte da formação profissional (LOULY; DOLGUI, 20II), o que ratifica a necessidade de seu estudo na fase de formação dos estudantes nos cursos de Administração.

Diante do exposto, considera-se relevante que os estudantes egressos dos Cursos de Administração tenham condições, não somente de internalizar a perspectiva das estratégias e técnicas de cálculos dos processos, mas também compreendam a lógica operacional envolvida durante a execução destas operações industriais. 


\section{CAMINHO METODOLÓGICO DA PESQUISA-AÇÃO}

As atividades de ensino na área de administração da produção criam interessantes possibilidades de articulação entre conhecimentos teóricos que circulam na academia e aqueles que são produzidos e usados nas situações práticas da realidade da manufatura empresarial, contribuindo como tentativa de ruptura da relação dicotômica entre os conhecimentos científicos e aqueles mobilizados na resolução de problemas da prática profissional. O entendimento dos conceitos acerca do conteúdo de Material Requirements Planning - MrP I, bem como da sua dinâmica de funcionamento e seus registros básicos para as sistemáticas de cálculos em uma organização empresarial, na visão de Dias, Sauaia e Yoshlzaki (20I3), são questões importantes do aprendizado do estudante de administração de maneira que ele consiga compreender como este conhecimento é utilizado na prática. Esta compreensão subsidia o desenvolvimento do estudante para as demais interfaces referentes a um sistema de produção e as evoluções ocorridas ao longo dos anos.

Focado nessa dicotomia, o estudo procura responder à questão: como organizar e conduzir uma aula com foco no conhecimento pedagógico do conteúdo vivenciado, por meio de uma ação didática simulada, que contribua para o entendimento teórico-prático dos conceitos estudados em Administração da Produção, tendo o conteúdo de MRP I como conteúdo alvo do estudo? Buscando responder esta problemática, foi organizada uma pesquisa exploratória (VERGARA, 2009) com o objetivo de elaborar uma proposta de atividade de ensino realizada em duas aulas. A primeira aula denomina-se "Apresentação do conteúdo científico", com a utilização da estratégia de aula expositivo-dialogada para apresentar a teoria, com uso de vídeos sobre o tema e desenvolvimento de exercícios descritivos, necessários para a realização dos cálculos de MRP I e a segunda aula denominada de "vivências mediadas", organizada em cinco etapas, apresentadas na Figura I.

Para investigar o desenvolvimento da proposta pedagógica do conteúdo, utilizou-se como caminho metodológico a pesquisa-ação (THIOLLENT, 2003), caracterizando-se pela ação direta do professor como pesquisador e 
participante-orientador da atividade proposta. As contribuições advindas do campo profissional quanto do acadêmico são importantes para a constituição do trabalho docente, mas não estão diretamente relacionadas com as ações didáticas e pedagógicas do professor. Ao adotar a postura de professor-pesquisador de sua prática, o docente "pode ser caracterizado, em maior ou menor grau, como um pensador ou pesquisador sobre o que se propõe a apresentar e debater com os alunos, inclusive sobre os efeitos de suas atividades sociais e educativas" (DA veIGA et al., 20I2, p.I3). Esse debate ocorre pelo uso da linguagem pedagógica e conduzido durante o processo educativo, permite uma reflexão da prática de construção do conhecimento durante a aula, com vista à possibilidade dos estudantes expandirem essas análises para as situações-problemas da vida profissional e suas possíveis transformações.

Uma pesquisa dessa natureza passa a ser uma investigação educativa, quando o que se pesquisa está relacionado com as práticas pedagógicas de determinado conteúdo de ensino. Conforme Morin (2004), a pesquisa-ação pode ser caracterizada como uma forma diferente de criação de saberes pela sua natureza participativa, tanto dos pesquisadores quanto dos participantes. Stenhouse (1993) argumenta que esse método de pesquisa é um meio em que o professor pode formular suas compreensões e proposições teóricas sobre determinado tema educativo e que esse venha a comprovar ou refutar, em suas aulas, as implicações de suas propostas.

O estudo classifica-se, ainda, como qualitativo, com coletas de dados por meio de observação direta do docente e por comentários escritos e verbalizados pelos participantes em relação à proposta didática desenvolvida (GIBBS, 2009). Como espaço temporal, foi realizada a primeira atividade, classificada como pré-teste, para a turma de Produção, Materiais de Logística II no ano de 2010 (33 estudantes matriculados no noturno e 26 no diurno). Após a análise dos resultados, foram realizadas melhorias na proposta inicial, a dinâmica foi novamente desenvolvida com turmas no ano de $201 \mathrm{I}$ (43 estudantes do noturno e 25 no diurno).

Para realizar a pesquisa foi utilizada, ainda, a observação participante por meio do registro de diário de campo das ações desenvolvidas pelos 
estudantes, bem como pela solicitação de um trabalho escrito com os resultados das negociações realizadas durante a atividade. Conforme Macke (2006, p.237), ao se analisar os dados coletados e "os ganhos de conhecimento obtido baseado na observação, a interação entre os participantes e a avaliação das ações na pesquisa-ação permitem relatar dificuldades encontradas em situações de inovação e mudança”. Para apresentar os resultados do estudo, estruturou-se o mesmo em duas partes: a primeira centra-se na revisão de referenciais sobre o tema; e, a segunda está relacionada aos procedimentos metodológicos e considerações referentes à proposta.

\section{O CONHECIMENTO PEDAGÓGICO DO CONTEÚDO ASSOCIADO A UMA AÇÃO DIDÁTICA SIMULADA EM AULA}

Um dos primeiros desafios ao iniciar a pensar uma proposta didática de simulação foi o de elaborar um exercício sistematizado que propiciasse usar os conceitos de Mrp no ambiente de aula, visando articular o entendimento pedagógico do conteúdo com as ações práticas, referentes aos processos produtivos e à definição do produto. O pressuposto para a definição do produto estava no fato de possibilitar o seu manuseio em sala de aula (uma das turmas com mais de 50 estudantes), não exigir recursos financeiros significativos (limitação orçamentária para a pesquisa), de os materiais serem manuseáveis e possibilitarem uma estrutura do produto que tivesse itens comprados e, com base nestas matérias primas, pudessem ser transformados em itens manufaturados e posteriormente montados. Outro fato que foi levado em consideração refere-se ao tempo de realização da atividade, pois toda a atividade simulada deveria ser realizada em uma aula de quatro períodos consecutivos de 60 minutos cada, totalizando 240 minutos para cada aula.

Baseado nestes pressupostos, foi estabelecido como produto um bloco de anotações contendo capa e contracapa, além de páginas internas. Como matéria prima utilizou-se papel do tipo $\mathrm{A}_{4}$ e posteriormente foram feitos os processos de corte, dobra e impressão da capa, além do corte das páginas internas. Assim foi possível verificar como um material pode ser transformado em outros componentes dentro do processo e como a 
\& OUTROS

quantidade de compra pode ser estabelecida com os desdobramentos dos itens de demanda dependente.

Figura I Síntese das etapas da vivência simulada em aula

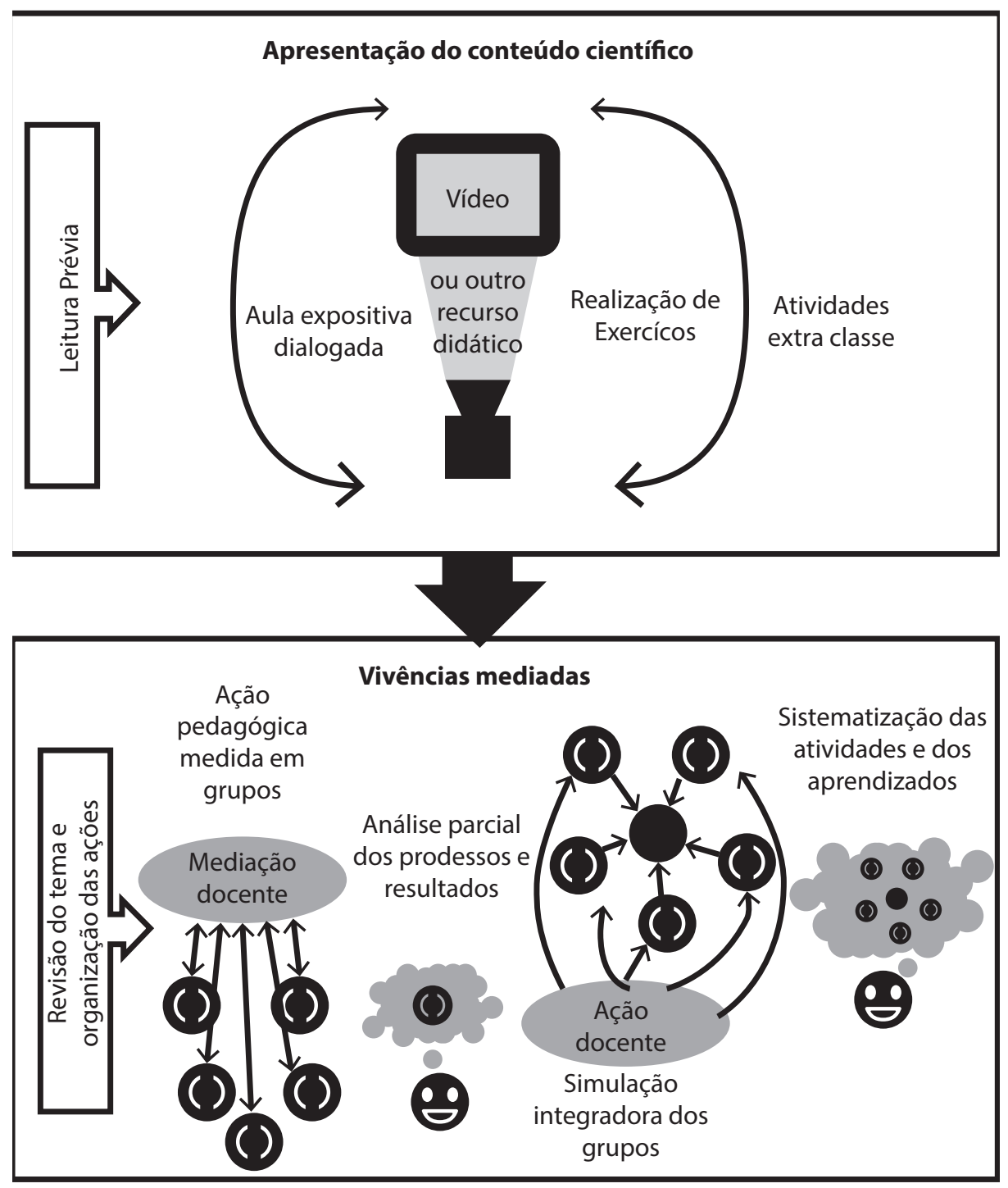


Para a montagem do produto foi estabelecido o uso de dois grampos a serem fixados na lateral esquerda do bloco e o acabamento com fita adesiva para dar proteção contra possíveis ferimentos com as pontas dos grampos. Assim, o produto deveria ser montado em uma linha de montagem com materiais oriundos diretamente de fornecedores externos e de itens manufaturados internamente. Também foi necessário o estabelecimento inicial de marcos temporais adequados à metodologia de cálculo do MRP. Como exemplos: a definição do lead time dos fornecedores e de fabricação, a quantidade de estoque de segurança de cada item, bem como a existência de lotes mínimos de compras de alguns itens.

Definido o produto, o pesquisador perguntou-se como os conteúdos seriam ministrados e como as atividades necessárias para a realização da simulação poderiam ser desenvolvidas. Na FiguraI, apresenta-se a síntese da proposta didática de gestão do processo de aula. A seguir é apresentada a descrição das etapas que compuseram a proposição do exercício didático da vivência simulada aqui em debate.

\section{PRIMEIRA AULA: APRESENTAÇÃO DO CONTEÚDO CIENTÍFICO}

Inicialmente, na primeira aula sobre o tema, houve a apresentação expositivo-dialogada do professor com a utilização de projeções para a explicação conceitual e, para o entendimento do tema foi realizado um exemplo. Na sequência, se fez um exercício orientado, com exposição da metodologia de cálculos do MRP, sendo este realizado pelo docente com o uso do quadro e de projeções de slides, mostrando sua aplicação.

\section{SEGUNDA AULA: VIVÊNCIAS MEDIADAS EM SALA DE AULA}

Para a organização desta aula, foram planejadas cinco etapas: revisão dos temas e definição das ações futuras; ação pedagógica mediada em grupos; análise parcial dos processos e resultados; simulação integrada; e, sistematização das atividades. A seguir são tratadas, de forma individual, cada uma das etapas. 


\section{Primeira etapa: revisão dos temas e definição das ações futuras}

Para a realização desta atividade os estudantes foram organizados em cinco grupos de trabalhos. A realização de uma atividade didática em grupos é importante, conforme Pardini et al. (2012, p.27) porque "[...] baseiase na noção de que os indivíduos aprendem mais quando constroem, discutem e transformam coletivamente o conhecimento". Aliado a este pensamento, o papel do docente, nesta proposta, é ampliado, pois este, além de realizar as explicações de fundamentação teórica, realiza um trabalho dinâmico mediando as ações desenvolvidas, baseadas no conhecimento e acompanhando os resultados desenvolvidos pelos grupos.

Após a organização do ambiente físico da aula, foi realizada a revisão dos cálculos realizados na semana anterior. Também foram reapresentados os dados da semana anterior e o docente orientou os grupos para a realização dos cálculos das quantidades no prazo estabelecido, de acordo com a metodologia do MRP I. Foi distribuída uma planilha-padrão para todos os grupos e a organização do layout dos postos de trabalho e demais atividades de cada empresa eram livremente definidas pelos grupos.

Em conjunto com os grupos, foi realizada a estrutura do produto (bloco de anotações) e com base nesta estrutura foram estabelecidos os números de postos de trabalho e as sequências de operações, realizando uma descrição sumária das etapas de fabricação e definindo as fichas dos processos produtivos. Foi estabelecido, também, o tempo inicial e final das semanas de produção para a realização dos cálculos, emissão das ordens de fabricação, manufatura dos produtos e sua entrega. Ao final de cada semana, o professor repassou a necessidade bruta do pedido (projeção de quatro semanas à frente).

Com base nessas informações, os grupos calcularam as necessidades de materiais e produtos em processo para cada demanda e emitiam as ordens de fabricação ou compra para cada etapa do processo.

O professor passou a ser o fornecedor de matéria prima (Folha A4) e solicitava que cada grupo realizasse seus pedidos de abastecimento na semana indicada em seus cálculos. Realizadas as atividades preparatórias para o andamento das atividades vivenciais de cálculo e produção, partiu-se para a segunda etapa. 


\section{Segunda etapa: Ação pedagógica mediada em grupos}

Realizadas as atividades iniciais de preparação, fez-se o início da primeira rodada da ação proposta. Neste momento, o professor indicou o início de qual semana estaria sendo feita a produção. É importante considerar, para melhor entendimento dos processos, que a produção seja iniciada com base em um produto considerado novo e a linha de montagem esteja vazia.

Para dar início ao processo, o docente divulgou os pedidos recebidos para a semana $X$ e com base nas informações da estrutura do produto e lead times de ressuprimentos de cada item (arbitrados pelo docente), devem ser realizados os cálculos e emitidas ordens de compras e de produção, para se iniciar o processo produtivo.

O docente passou a ser o fornecedor de matérias primas, e para isso recebia as ordens de compras. O tempo de ressuprimento, estabelecido inicialmente foi de uma semana, para que o docente pudesse organizar a entrega das mercadorias aos grupos sem atrasos.

Finalizada a primeira semana, iniciou-se a segunda, quando foi feito o pagamento do material para as empresas e disponibilizada a quantidade de pedidos para a semana seguinte de programação. Desta forma, o docente indicou a finalização de cada semana e o início da subsequente, retomando o ciclo de programação (não se recomenda ultrapassar quatro ciclos).

\section{Terceira etapa: análise parcial dos processos e dos resultados}

Finalizadas as semanas de produção estabelecidas para a simulação, fez-se uma parada na atividade para solicitar aos estudantes que comentassem sobre as experiências de cada grupo e a verificação do andamento dos cálculos e respectivos desempenhos de suas linhas de montagem, ou seja, uma reflexão na ação.

Neste momento, o docente solicitou que os grupos apresentassem a quantidade de produtos em processos e manufaturados ao final da última semana de trabalho executada e fizessem a comparação dos dados referentes aos que foram projetados e dos que foram executados. Caso houvesse divergências, deveriam solicitar comentários explicativos dos motivos das discrepâncias entre a projeção de produção e sua execução. 
Baseado nos comentários dos grupos tornou-se importante solicitar que fossem feitas reflexões sobre as ações realizadas e que propostas de correções nos processos ou nos cálculos seriam necessárias para dirimir essas lacunas.

\section{Quarta etapa: simulação integrada}

Esta etapa tem por finalidade a observação conjunta das operações de montagem. Foi organizado um grupo de cinco estudantes, oriundos um de cada grupo que seriam os montadores da nova linha de manufatura. $\mathrm{O}$ seu grupo de origem passa a ser o responsável pelos cálculos e diretrizes de sua parte do processo produtivo. Cada grupo passou a ser exclusivamente o responsável pela programação da produção de apenas uma parte do processo.

Realiza-se o estabelecimento de que as ordens de fabricação e de compras sejam impressas e encaminhadas, na semana de execução, para a linha de montagem e para o fornecedor, respectivamente. Desta forma, o professor organizou no centro da sala uma linha de manufatura e os grupos em volta desta, como programadores de produção e solicita um voluntário de cada grupo para fazer parte do processo de chão de fábrica.

Ao início de cada semana de produção, os programadores necessitam liberar as ordens para a fábrica para que estes a executem. Com base nas programações das demandas futuras, a programação calcula as necessidades da próxima semana. O fluxo de informações também necessita ocorrer da fábrica para os programadores, informando quantas peças foram feitas no período e se houve atrasos ou problemas de qualidade. Esta etapa inicia com a linha vazia e o ciclo deve ser feito até que saia o primeiro produto na linha.

\section{Quinta etapa: Sistematização das atividades}

Depois de finalizado o ciclo completo das atividades, o docente realiza a sistematização final da aula solicitando que os estudantes façam uma comparação entre o que foi calculado e o estoque físico existente em cada posto de trabalho da linha de montagem, bem como a análise dos dados e fluxos produtivos e de informações que foram realizadas no decorrer da 
atividade. Este é um momento rico para a internalização de conceitos e resultados, apresentando-se os fluxos de produtos, processos de fabricação, produtos acabados, operações realizadas, problemas de qualidade, medições de tempo de produção, entre outros tópicos e conceitos que são necessários para a realização da simulação.

Para finalizar a atividade solicita-se, ainda, que cada estudante faça um relatório por escrito, realizando uma reflexão sobre o exercício. A realização desta tarefa é importante para a internalização dos conceitos estudados e das dinâmicas realizadas, possibilitando a fixação do aprendizado e o desenvolvimento de novas explicações e compreensões sobre os conteúdos trabalhados. A entrega do relatório foi solicitada para a aula seguinte. 


\section{ALGUMAS REFLEXÕES SOBRE A EXECUÇÃO DA DIDÁTICA PROPOSTA}

Neste tópico são expressas algumas discussões e reflexões sobre a implantação da metodologia proposta, de forma a propiciar a experiência vivencial mediada. Por meio da abordagem metodológica de pesquisa qualitativa, buscou-se identificar as categorias de investigação para posterior análise, tendo como tipologia de pesquisa, quanto aos procedimentos, conforme Thiollent (2003), do tipo pesquisa-ação; e como populaçãoreferência estudantes do Curso de Administração de uma Universidade Federal, localizada no interior do Estado do Rio Grande do Sul, realizada no primeiro semestre do ano de 201 em duas turmas (noturno e diurno). De acordo com Gil (1999), a amostragem caracteriza-se como não probabilística aliada à questão de acessibilidade, nesse caso estudantes matriculados no campus, no curso e na disciplina em questão.

O que motivou a realização dessa pesquisa foi quando o docente percebeu em 2009, ao ministrar pela primeira vez o conteúdo de MRP a existência de dificuldades dos estudantes em compreender o tema somente pela forma tradicional de aula (expositivo-dialogada com uso de projeções de slides e do auxílio da lousa para desenvolvimento do exercício). No ano seguinte, o docente elaborou uma proposta de dinâmica de aula simulada, apresentada no item anterior deste estudo. Inicialmente o docente apresentou a proposta, para a nova turma, da atividade vivencial simulada sobre o tema, sendo que o mesmo exercício seria realizado simultaneamente nos aspectos teóricos tradicionais (aula expositivo-dialogada) e numa segunda aula, por meio de atividades simulado-mediadas, de forma a apresentar as implicações do conteúdo desenvolvido. As turmas aceitaram a proposta e na semana seguinte foram realizadas as atividades relatadas.

Em relação às experiências realizadas na primeira aula, ou seja, pelo método tradicional de aula expositivo-dialogada, constatou-se que os estudantes se mantinham passivos, apenas acompanhando as explicações e orientações do docente e na busca da resolução dos exercícios propostos. Alguns, eventualmente, faziam intervenções no sentido de buscar outras 
explicações sobre o tema proposto com vistas à compreensão teórica do tema ou para a resolução dos cálculos propostos.

O segundo desafio foi em relação à orientação inicial dos estudantes no início da segunda aula. Como as experiências didático-pedagógicas dos estudantes eram da perspectiva da aula tradicional, verificou-se a dificuldade de mobilizar a turma para a realização de atividades focadas de forma diferente, além das de resolver teoricamente os exercícios propostos. Percebeu-se que, quando se exige uma postura focada na ação direta do estudante de forma que ele passa a ser o agente fundamental para o resultado do desempenho do grupo, encontraram-se algumas resistências ou dificuldades do entendimento do seu novo papel na atividade. Conforme relato da Estudante E "[...] primeiramente os grupos encontraram dificuldades na organização”. Como resultado desse fato, a fase inicial de organização da aula, que havia sido pensada para io a I5 minutos, foram gastos 40 minutos. Percebeu-se, também, que no início da segunda aula alguns estudantes estavam realizando a atividade em tom de brincadeira, sem se preocupar com os conceitos que estariam sendo vivenciados simuladamente, ao longo da atividade, o que exigiu novas mediações docentes.

Vencidas essas barreiras iniciais e realizada a primeira semana de cálculo de produção, outro ponto observado e que exigiu uma nova atenção do docente foi o fato da definição do início e fim de cada período de programação. Conforme o Estudante F, para que haja um entendimento das questões temporais, "[...] não basta entender um fato isolado dentro do processo, pois tudo está interligado, inclusive no tempo". Essa dificuldade apresentada pelos estudantes exigiu que, no momento dos cálculos, fossem utilizadas cores diferentes para cada semana. Assim, facilitou a compreensão do fator temporal, devido à dificuldade inicial de entender que o período real de uma semana e o período de semana do exercício, o qual durava apenas alguns minutos.

As planilhas de cálculo de cada item foram estruturadas na lousa da sala e os estudantes realizavam o acompanhamento em seus cadernos. Devido ao tamanho da sala, do número de alunos e das quantidades de itens 
trabalhados, houve dificuldade visual, no sentido da leitura dos números no quadro em função do tamanho da letra que precisava ser utilizada para que todo o exercício pudesse ser estruturado no quadro. Como recomendação, sugerem-se para novas experiências que o docente traga impressas as planilhas de cálculos e um formato pré-estabelecido das liberações de ordens de compras e de produção.

Realizar a tarefa proposta em aula foi uma atividade complexa. "Chegar a um PMP que compatibilize as necessidades de produção com a capacidade disponível não foi fácil, ainda que os produtos envolvidos não exigissem muitas operações" (ESTUDANTE s).

Conforme pode ser observado nos comentários da estudante $S$ e muito embora o exercício tenha utilizado um produto simples, com poucos itens e de fácil manuseio para a atividade operacional, não deixou de exigir a base conceitual do MRP e seus desdobramentos para que o processo operacional pudesse ocorrer. Para a Estudante A, "[...] com a prática em sala de aula o método (MRP) se tornou fácil, pois vimos como se faz na prática, ficou mais fácil de entender". O momento de simulação integradora dos grupos realizada na aula de vivências mediadas é uma sistemática de ação tem por princípio apresentar as inter-relações existentes entre os diversos setores de uma organização empresarial e como elas podem ou não interferem para no alcance dos resultados como um todo. Os objetivos de cada grupo periférico são parciais e intercomplementares para o alcance da meta geral que era finalizada nas ações da equipe da linha de montagem.

Observou-se que todos os grupos estavam realizando as ações para a consecução da tarefa. Como a didática, neste momento, limitava a comunicação de maneira escrita, cada grupo procurava realizar a atividade da sua forma, sem a busca de uma comunicação, mesmo que escrita, com os demais. Cada um fazia sua parte e ao finalizar os cálculos realizavam a emissão das ordens de compras - OC e as ordens de fabricação - OF repassando-as para as respectivas partes interessadas.

No primeiro ciclo de fabricação da ação integradora, a equipe que representava a linha de montagem estava sem nenhum produto a ser manufaturado. Ela estava no aguardo das deliberações das equipes periféricas 
para darem continuidade as suas atividades. A aparente parada das pessoas da linha busca mostrar a importância das questões de organização de uma empresa e revela que houve o entendimento dos conceitos acerca da montagem ser realizada somente mediante o envio de OFs. Essa postura do grupo central propiciou um comentário na sistematização final da aula no sentido que pode ser evidenciado o lead time entre a emissão da OF e o seu processo de fabricação, estudado na teoria.

Diferentemente da estratégia de competição envolta no jogo de empresa, a didática de vivências mediadas busca oportunizar o entendimento dinâmico dos conceitos por meio de uma simulação que não tem por objetivo premiar o grupo que apresenta o melhor resultado. Nesta proposta, muito embora em alguns momentos da aula as ações dos grupos fossem realizadas em diversos grupos, ao analisar a atividade como um todo é possível estimular a ocorrência de uma ação colaborativa, pelo fato do resultado da execução da meta final proposta ser a mesma para toda a turma, independente do seu local de trabalho. Esta ação oportuniza ilustrar, aos estudantes, as relações existentes entre os diversos setores de trabalho de uma organização empresarial e quais são as repercussões de suas ações para os demais setores e para o resultado final.

Por fim, mesmo que se tenha percebido nos relatos dos estudantes uma melhor compreensão dos conceitos com a utilização desta sistemática, conforme o Estudante R, mesmo depois de realizada e analisada a tarefa, "[...] poderíamos repetir o processo para ficar mais clara e assim melhorar o aprendizado”. Fica evidente, no comentário do estudante, que após a realização da reflexão-sobre-a-ação ainda se faz necessária uma nova realização dessa atividade didático-pedagógica. 


\section{CONSIDERAÇÕES FINAIS}

A realização dessa atividade tinha como objetivo realizar uma sistemática didático-pedagógica que possibilitasse aos estudantes da disciplina de Produção do curso de Administração a compreensão prática do uso do MRP I. Para a realização de atividades desta natureza exige-se do docente, além do domínio do conteúdo, uma preparação prévia do material, foco na condução do processo de aula, pelo fato das abordagens conceituais serem realizadas de forma geral, e as ações realizadas simultaneamente, com cinco grupos.

Pode-se perceber que, num primeiro momento, os estudantes apresentaram dificuldade de entender o que se pretendia, pois estavam acostumados à passividade de sua participação em aula. Como a sua participação torna-se imprescindível para esse outro processo de aula, devido ao fato que se faz necessário um trabalho efetivo em equipe para serem realizadas todas as atividades exigidas pelo exercício, inicialmente percebeu-se certa resistência à adesão, porém com o transcorrer das dinâmicas, os estudantes se envolviam e passavam a se comprometer com as mesmas.

Neste sentido, o caráter vivencial da atividade desenvolvida por meio das vivências mediadas, propicia que o papel do docente seja o de mediador do processo de ensino, aliados à necessidade de mudança de postura do estudante focada para o seu aprendizado focado para seu perfil profissional. O estudante passa a ser o protagonista de um processo educacional centrado em objetivos sociais atingidos por dinâmicas do trabalho coletivo no ambiente universitário. Essas relações permitem inferir que as significações concretas oriundas desta didática conduzem ao termo "constituir o conhecimento" ao invés de "treinar" ou de "formar", pois este último remete a uma série de questionamentos sobre o que se tem feito na educação superior no País.

Como aprendizado docente, destaca-se que essa sistemática de aula possibilita um envolvimento ativo do estudante e potencializa o trabalho mediado do docente em orientar os grupos a encontrarem soluções frente 
às situações-problema, existentes em seus processos produtivos, mesmo em situações didáticas.

Destaca-se, também, que o fato de as atividades serem realizadas com duas turmas, apenas, não permite generalizações e limita-se a um contexto específico: ensino do MRP I. Novas pesquisas e em outros contextos, com diferentes objetos e em diversos níveis do curso de Administração são bem vindas. Além disto, a aplicação da dinâmica com estudantes em cursos públicos e em instituições privadas, com fins comparativos, podem trazer significativos subsídios.

Diante do exposto, ao abordar o ensino da Administração da Produção, ainda se fazem necessárias outras abordagens, exercícios e pesquisas educacionais sobre a temática apresentada, bem como uma reflexão dos conteúdos que são desenvolvidos em aula para dar suporte teórico às futuras decisões reais que o estudante egresso poderá vivenciar como Administrador. 


\section{REFERÊNCIAS}

ARAGÃO, J.E.O.S. Cursos de Administração e Politicas de Avaliação de Avaliação do Ensino Superior no Estado de São Paulo (1995-2006). Tese de Doutorado. Programa de Pós Graduação em Educação da Universidade Federal de São Carlos, 2008.

BRASIL, CNPQ - Conselho Nacional de Desenvolvimento Científico e Tecnológico. Tabela das áreas do conhecimento. Disponível em: <http://www.cnpq.br/ areasconhecimento/6.htm > Acesso em 08/12/2012.

. Conselho Nacional de Educação. Câmara de Ensino Superior. Resolução 04, de 13 de julho de 2005. Disponível em: <http://portal.mec.gov.br/cne/arquivos/pdf/ rces004_05.pdf > Acesso em 08/12/2012.

. Comissão de Aperfeiçoamento de Pessoal de Nível Superior - CAPES. Critérios de Avaliação trienal. Triênio avaliado 2004 - 2007. Área de Avaliação: administração/ turismo. 2006. Disponível em: <http://www.capes.gov.br/images/stories/download/ avaliacao/CA2007_AdministracaoTurismo.pdf > Acesso em 03/01/2013.

CLOSS, L. Q.; ARAMBURU, J. V.; ANTUNES, E. D. Produção científica sobre o ensino em administração: uma avaliação envolvendo o enfoque do Paradigma da Complexidade. Revista Gestão.Org, v. 7, n. 2, p. 150-169, 2009.

CORRÊA, H.L.; GIANESI, I. G. N. Just in time, MRP II e OPT: um enfoque estratégico. 2.ed. São Paulo: Atlas, 1994.

DA VEIGA, C.H.A.; RITTER-PEREIRA, J.; BRUTTI, T.A.; MALDANER, O.A. Horizontes do professor-pesquisador no contexto de sua prática docente. In: Simpósio de Pesquisa em Educação da Região Sul, 9., 2012, Caxias do Sul. Anais... Caxias do Sul: ANPEDSUL, 2012.

DEPEXE, M.D.; DORNELES, J.B.; COSTA, A.C.F.; SANTOS, D.G.; HEINECK, L.F.M. Apresentação de um jogo didático como ferramenta de apoio ao ensino da produção enxuta. Revista Gestão Industrial, v. 2, n. 4, p. 140-151, 2006.

DIAS, G. P. P.; SAUAIA, A. C. A.; YOSHIZAKI, H. T. Y. Estilos de aprendizagem Felder-Silverman e o aprendizado com jogos de empresas. Revista de Administração de Empresas, São Paulo, v.53, n. 5, p. 469-484, 2013.

FRÖNER, F. Qualidade do ambiente laboral e relações de trabalho. Revista do Processo de Trabalho e Sindicalismo, n.4, Porto Alegre: HS Editora, 2013.

GHEDIN, E. Professor reflexivo: da alienação da técnica à autonomia da crítica. In PIMENTA, S.G.; GHEDIN, E. Professor reflexivo no Brasil: gênese e crítica de um conceito. 4.ed. São Paulo: Cortez, 2006.

GIL, A. C. Métodos e técnicas de pesquisa social. 5.ed. São Paulo: Atlas, 1999.

GIBBS, G. Análise de dados qualitativos. Porto Alegre: Artmed, 2009.

HARDING, H.A. Administração da produção. São Paulo: Atlas, 1992. 
JARAUTA-BORRASCA, B.; MEDINA-MOYA. La formación pedagógica inicial del profesorado universitario. Repercusión en las concepciones y prácticas docentes. Revista Internacional de Investigación en Educación, Bogotá, v.1, n.2, p. 357-370, 2009.

KRAJEWSKI, L. J.; RITZMAN, L.; MALHOTRA, M. Administração da produção e operações. 8.ed. São Paulo: Pearson Prentice Hall, 2009.

LÉGER, P.M.; CRONAN, P.; CHARLAND, P.; PELLERIN, R.; BABIN, G.; ROBERT, J. Authentic OM problem solving in an ERP context. International Journal of Operations \& Production Management, v. 32, n.12, p. 1375-1394, 2012.

LEONTIEV, A. N. Uma contribuição à teoria do desenvolvimento da psique infantil. In Vigotsky, Lev. S. Linguagem, desenvolvimento e aprendizagem. São Paulo: Ícone, 1988.

LOULY, M.-A.; DOLGUI, A. Optimal time phasing and periodicity for MRP with POQ policy. International Journal of Production Economics, v. 131, n. 1, p. 76-86, 2011.

MACKE, J. A pesquisa-ação como estratégia de pesquisa participativa. In: GODOI, C. K.; BANDEIRA-DE-MELO, R.; SILVA, A. B. Pesquisa qualitativa em estudos organizacionais: paradigmas, estratégias e métodos. São Paulo: Saraiva, 2006.

MARANHÃO, C. M. S. A.; DE PAULA, A.P. P. História e Projetos da Pedagogia Crítica: Trilhando um Caminho Possível no Ensino da Administração. In: EnANPAD, 32., 2008, Rio de Janeiro. Anais... Rio de Janeiro: Anpad, 2008.

MARTINS, P. G.; LAUGENI, F. P. Administração da produção. 2.ed. São Paulo: Saraiva, 2006.

MATTOS, P. L. C. L. de. "Relações Teoria-Prática” em Administração: o que desaparece nesse "Buraco Negro". In: EnANPAD, 34., 2010, Rio de Janeiro. Anais... Rio de Janeiro: Anpad, 2010.

MORIN, A. Pesquisa-ação integral e sistêmica: uma antropopedagogia renovada. Rio de Janeiro: DP\&A, 2004.

MOTA, G. S.; MELO, D. R. A.; PAIXÃO, R. B. O Jogo de empresas no processo de aprendizagem em Administração: o discurso coletivo de alunos. Revista de Administração Contemporânea, v. 16, n. 3, p. 342-359, 2012.

NICOLINI, A. Qual será o futuro das fábricas de administradores? Revista de Administração de Empresas, v.43, n.2, p.44-54, 2003.

OLIVEIRA, M.A.; SAUAIA, A.C.A.; GARCIA, P.A.A.; MOREIRA, J.S. Relação entre Conhecimento e Desempenho Gerencial: Análise do Aprendizado dos Participantes de um Jogo de Empresas. In: EnANPAD, 34., 2010, Rio de Janeiro. Anais... Rio de Janeiro: Anpad, 2010.

PARDINI, D.J.; SILVA JÚNIOR, A.B.; GONÇALVES, C.A.; MELO P.A. Redes de aprendizagem: uma proposta metodológica no ensino de executivos. Revista de Ciências da Administração, v.14, n.33, p.25-40, 2012. 
PIANA, J.; ERDMANN, R. H. Avaliação de simulação empresarial: um estudo na Universidade Autônoma de Lisboa. Administração: Ensino e Pesquisa, v.14, n.3, p. 557-589, 2013.

PLATT, A.A.; KLAES, L. S. Utilizando o sistema integrado de gestão (ERP) no apoio ao ensino de Logística e Gestão da Cadeia de Suprimentos. Revista de Ciências da Administração, v. 12, n. 28, p. 224-241, 2010.

PUENTES, R. V.; AQUINO, O. F.; QUILLICI NETO. Profissionalização dos professores: conhecimentos, saberes e competências necessários à docência. Educar. Curitiba: UFPR, n. 34, p. 169-184, 2009.

ROMAN, D. J.; MARCHI, J. J.; ERDMANN, R. H. A abordagem qualitativa na pesquisa em Administração da Produção no Brasil. Revista de Gestão, v. 20, n. 1, p. 131-144, 2013.

SANTOS, J.A. Learning Environments in Management Education: in Search of Meaning. In: EnANPAD, 33., 2009, São Paulo. Anais... São Paulo: Anpad, 2009.

SANTOS, L. L. S.; ALCADIPANI, R.. Por uma Epistemologia das Práticas Administrativas: a Contribuição de Theodore Schatzki. In: EnANPAD, 34., 2010, Rio de Janeiro. Anais... Rio de Janeiro: Anpad, 2010.

SATOLO, E. G. Modelo de simulação aplicado ao conceito da produção enxuta no ensino de engenharia de produção. In: Encontro Nacional de Engenharia de Produção, 31., 2011, Belo Horizonte. Anais... Belo Horizonte, 2011.

SEETHAMRAJU, R. Enterprise systems software in the business curriculum: aligning curriculum with industry requirements. In: LOWRY, G. R.; TURNER, R. L. Information systems and technology education: from the university to the workplace. Hershey, USA: IGI Global, 2007.

SHINGO, S. O sistema Toyota de produção do ponto de vista da engenharia de produção. 2.ed. Porto Alegre: Artmed, 1996.

SCHÖN, D.A. Educando o profissional reflexivo: um novo design para o ensino e a aprendizagem. Porto Alegre: Artmed, 2000.

SHULMAN, L. S. Conocimiento y enseñanza: fundamentos de la nueva reforma. Professorado. Revista de Currículum y Formación del Professorado, v 9, n.2, 2005.

SLACK, N.; CHAMBERS, S.; JOHNSTON, R. Administração da Produção. 2.ed. São Paulo: Atlas, 2002.

SLACK, N.; LEWIS, M.; BATES, H. The two worlds of operations management research and practice. Can they meet, should the meet? International Journal of Operations \& Production Management, v. 24, n. 4, p. 372-387. 2004.

STEIN, E. Fundamentar e pressupor: a caminho do dito e do dizer. In A caminho de uma fundamentação pós-metafísica. Porto Alegre: EDIPUCRS, 1997.

STENHOUSE, L. La investigación como base de la enseñanza. 2.ed. Madrid: Ediciones Morata, 1993. 
THIOLLENT, M. Metodologia da pesquisa-ação. 12.ed. São Paulo: Cortez, 2003.

TUBINO, D.F. Planejamento e controle da produção: teoria e prática. São Paulo: Altas, 2008.

VERGARA, S. C. Projetos e relatórios de pesquisa em administração. 10.ed. São Paulo: Atlas, 2009.

VIGOTSKY, L. S. Pensamento e linguagem. 4.ed. São Paulo: Martins Fontes, 2008.

VILLARDI, B. Q. Implicações da Aprendizagem Experiencial e da Reflexão Pública sobre o Campo, para o Ensino de Pesquisa Científica e a Formação de Mestres em Administração. In: EnANPAD, 34., 2010, Rio de Janeiro. Anais... Rio de Janeiro: Anpad, 2010 .

ZEICHNER, K. Novos caminhos para o practicum: uma perspectiva para os anos 90. In: NOVOA, A. Os professores e sua formação. Publicações Don Quixote: Lisboa, Portugal, 1992. 


\section{DADOS DOS AUTORES}

\section{CRISTIANO HENRIQUE ANTONELLI DA VEIGA^ chadaveiga@gmail.com} Doutor em Educação nas Ciências pela Unijuí

Instituição de vinculação: Universidade Federal de Santa Maria

Palmeira das Missões/RS - Brasil

Áreas de interesse em pesquisa: Teoria da Atividade, Integração de Aprendizagens, Ensino de Graduação em Administração e Administração da Produção.

Rua Sete de Setembro, 273, ap. 01 Centro Palmeira das Missões/RS 98300-000

\section{LENIR BASSO ZANON bzanon@unijui.edu.br}

\section{Doutora em Educação pela Unimep}

Instituição de vinculação: Universidade Regional do Noroeste do Estado do Rio

Grande do Sul

Ijuí / RS - Brasil

Áreas de interesse em pesquisa: Educação e formação de professores.

\section{LUIS CARLOS ZUCATTO luiszucatto@yahoo.com}

\section{Mestre em Administração pela UFRGS}

Instituição de vinculação: Universidade Federal de Santa Maria

Palmeira das Missões/RS - Brasil

Áreas de interesse em pesquisa: Ensino em Administração, Inovação, Logística e

Sustentabilidade. 